\title{
IMPLEMENTAÇÃO DO SISTEMA DE NÍVEL 2 NOS ALTOS FORNOS DA TKCSA*
}

\author{
Akira Yoshida ${ }^{1}$ \\ Alan Jose Santos de Almeida ${ }^{2}$ \\ André Wulff Hirano ${ }^{3}$ \\ Deilton de Oliveira Souza \\ João Vitor Gomes Figueiredo ${ }^{5}$
}

\section{Resumo}

Este trabalho apresenta o sistema de Nível 2 recentemente implementado nos Altos Fornos da TKCSA cujos principais objetivos foram: substituir o sistema antigo com problemas de instabilidade e falta de flexibilidade; auxiliar Operação e especialistas da Unidade Técnica fornecendo informações elaboradas a partir de dados obtidos nos demais sistemas (Nível 1 e Laboratório); enviar set-point ao Nível 1; enviar dados de consumo e produção ao sistema MES; etc. Com a implementação foi possível reduzir o tempo gasto pelos especialistas nas atividades de compilação de dados em planilhas, padronizar a forma de tratamento dos dados, bem como, elevar a confiabilidade das informações pela eliminação de erro de digitação. O sistema tem operado com elevada estabilidade e disponibilidade, atendendo perfeitamente 0 que foi proposto, de modo que a TKCSA planeja estender para demais plantas da área de Redução.

Palavras-chave: Sistema de nível 2; Alto forno; Virtualização; Otimização de processo.

\section{LEVEL 2 SYSTEM IMPLEMENTATION IN BLAST FURNACES OF TKCSA Abstract}

This paper presents the Level 2 system recently implemented in Blast Furnaces of TKCSA whose main objectives were to replace the previous system with problems of instability and lack of flexibility; support Operation and Technical Unit experts providing information elaborated from data obtained in other systems (Level 1 and Laboratory); send set-point to the Level 1; send consumption and production data to the MES system; etc. With the implementation was possible to reduce the time spent by the specialist for compiling data in spreadsheets activities, standardize the data processing activity, as well as increase the reliability of information by eliminating typo. The system is operated with high stability and availability, meet exactly what was proposed, so that the CSA plans to extend to other plants of the Iron Makin area.

Keywords: Level 2 system; Blast furnace; Virtualization; Process optimization.

1 Engenheiro Eletricista, Consultor de Automação e Otimização de Processos Siderúrgicos, YOSHIDA Engenharia e Consultoria Ltda. - ME, Vitória, ES, Brasil.

2 Licenciatura Plena em Computação, Analista de Processos, Unidade Técnica da Redução, TKCSA, Rio de Janeiro, RJ, Brasil.

3 Engenheiro Metalurgista, Engenheiro de Processo, Unidade Técnica da Redução, TKCSA, Rio de Janeiro, RJ, Brasil.

4 Engenheira de Controle e Automação, Engenheiro de Automação Pleno, Engenharia do Alto Forno, TKCSA, Rio de Janeiro, RJ, Brasil.

5 Bacharel em Sistemas de Informação, Projetista de TI, Departamento de Tecnologia da Informação e Inovação, IHM Engenharia, Belo Horizonte, MG, Brasil. 


\section{INTRODUÇÃO}

O tempo de resposta de Alto Forno a uma ação é muito lento. No caso de alteração de carga, por exemplo, o efeito a qualidade de gusa/escória, aparece somente depois de 8 horas. Aliado a este fato, a necessidade de observar grande volume de dados de processo, fazem com que a utilização de Nível 2 torna indispensável na operação estável da Planta. O sistema original tinha pouca funcionalidade e muita instabilidade, além de não permitir modificações e melhorias, o que alavancou a implantação de um novo sistema a ser descrito neste trabalho.

\section{MATERIAIS E MÉTODOS}

\subsection{Alto Forno}

O Alto Forno é um reator metalúrgico de contra corrente destinado a produção do ferro gusa. Este por sua vez, é obtido a partir da redução de óxidos de ferro em contra corrente com o elemento redutor ( $\mathrm{CO}$ e H2). O ferro gusa é uma solução ferro-carbono, composta de 90 a 95\% de ferro e 3,0 a 4,5\% de carbono e elementos de liga como Si e Mn. De forma simplificada, trata-se de um processo onde deve ser feito o controle do processo tanto do ponto de vista de balanço de massa como o de energia. Conforme figura 1

\section{Gás de Alto Forno}

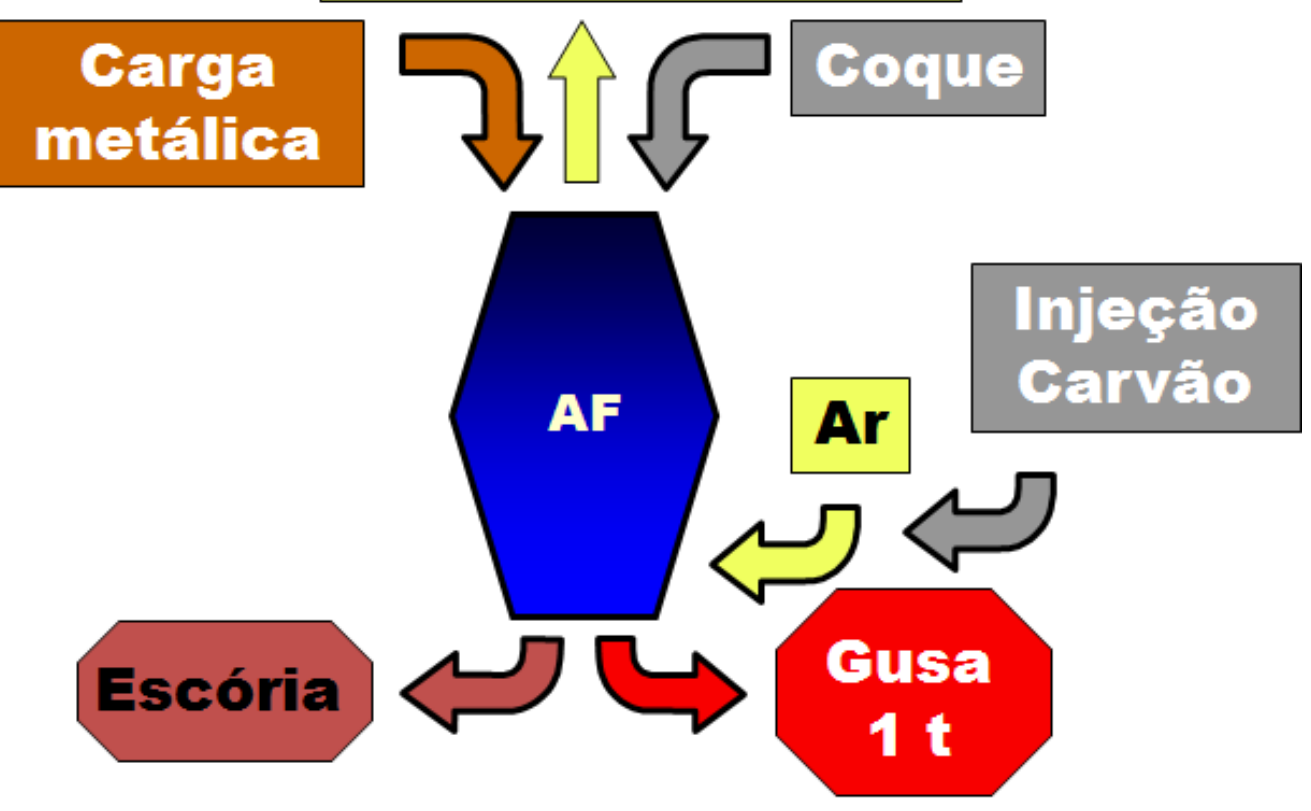

\section{MASSA DO QUE ENTRA = MASSA DO QUE SAI CALOR QUE ENTRA=CALOR QUE SAI}

Figura 1: Esquema do Reator em contra corrente.

Especificamente no Alto Forno, instrumentos modernos para observação e controle, monitoração de equipamentos e supervisão da operação por computadores vem sendo instalados conforme a evolução dos processos siderúrgicos [1]. 


\subsection{Sistema de Nível 2}

O sistema de Nível 2 desempenha o papel de otimização e apoio operacional, transformando grande volume de dados de processo em informações e disponibilizando uma visão ampla da situação operacional, de forma ágil e precisa. A sua posição na pirâmide da automação do modelo ISA95.01 [2] está mostrada na figura 2:

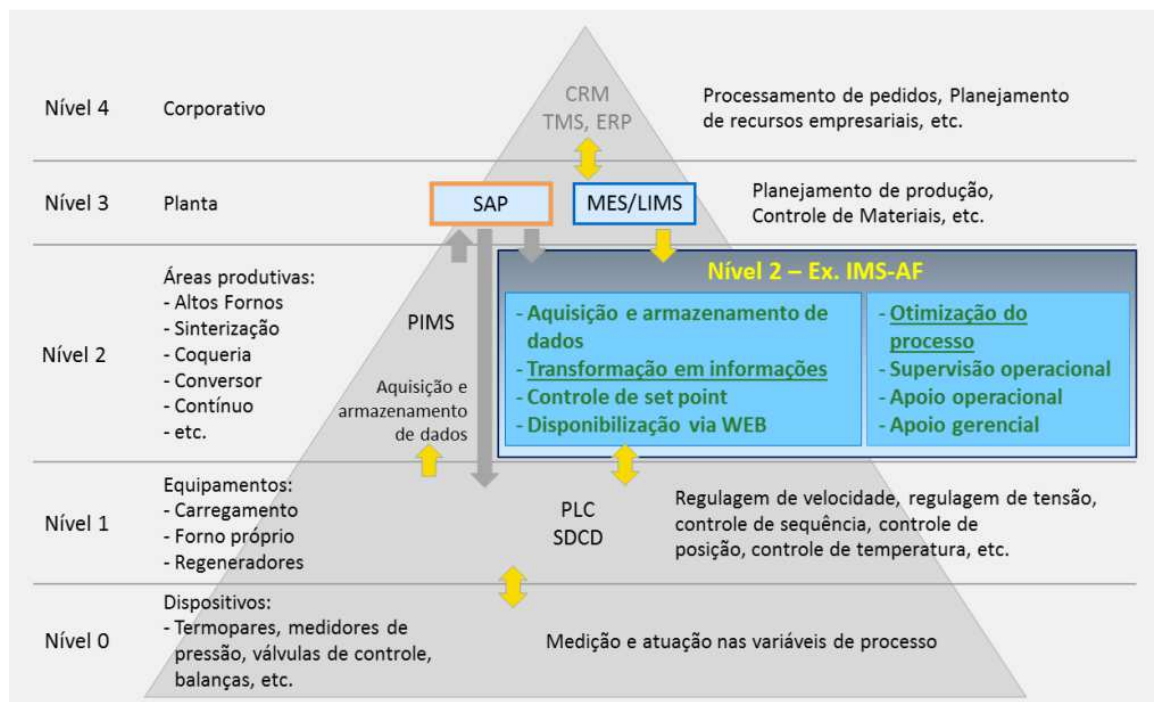

Figura 2: Atuação do sistema de Nível 2 na pirâmide da automação

\subsection{Sistema de Nível 2 Predecessor}

\subsubsection{Características do sistema predecessor}

$\mathrm{O}$ diagrama da figura 3 mostra a configuração do sistema predecessor. Dos quatro servidores, dois eram virtualizados e executados no Dell PowerEdge 2950 III. O servidor de BD comunicava com o Matrikon (OPC server), através do qual se obtinha os dados de Nível 1.

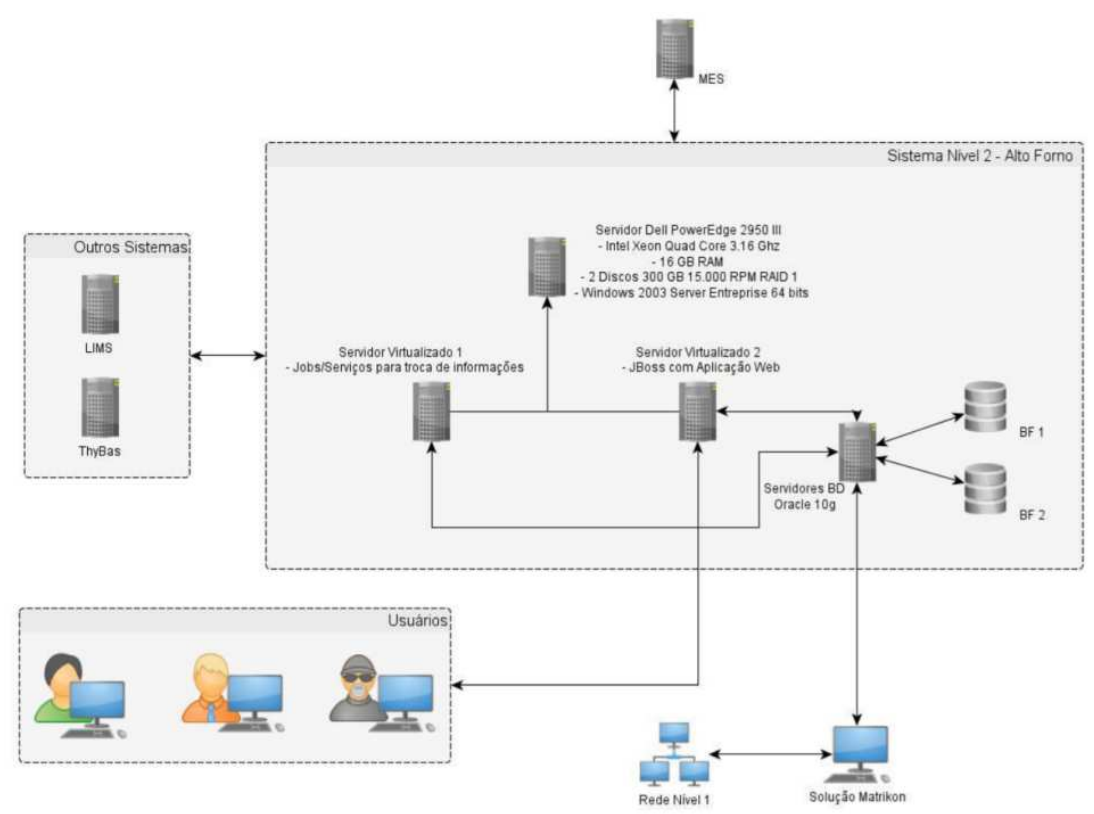

Figura 3: Configuração do sistema predecessor 
O ambiente do sistema predecessor era baseado em plataforma Java que possui algumas características que são incompatíveis com o Windows.

\subsubsection{Problemas do sistema predecessor}

- Perda de performance devido a virtualização sobre uma única máquina.

- Impossibilidade de ativar o programa em Java (JOBS) como serviço do Windows.

- Necessidade dos JOBS serem ativados pelo scheduler do Windows, o que sobrecarrega o servidor.

- JOBS com erros.

- Dependência do servidor OPC em suporte e licença da Matrikon.

- Dificuldade em atender novas necessidades da Operação.

- Limitação da interface web em navegação entre telas operacionais.

- Falhas na geração de relatórios impressos a partir da interface web.

- Falta da funcionalidade de exportação dos relatórios para planilha Excel.

- Poucas bibliotecas nativas para conexão direta com o Nível 1 devido a plataforma Java.

\subsection{Nível 2 dos Altos Fornos da TKCSA - Sistema Novo}

O sistema de nível 2 dos Altos Fornos da TKCSA foi implementado pela IHM Engenharia para auxiliar na otimização e supervisão operacional através de aquisição e armazenamento dos dados, compilação dos mesmos e disponibilização dos resultados de forma ágil.

\subsubsection{Topologia do sistema}

A aquisição de dados de processo é feita através de acesso aos servidores OPC do sistema de Nível 1 que disponibilizam tanto instantâneo, como histórico. Os resultados de análise química das matérias primas e de produtos são obtidos no sistema LIMS. Na troca de mensagem como o MES contempla recebimento da programação operacional e envio de consumo e produção. A interação com os usuários é feita através de aplicação desktop distribuída e atualizada via Clickonce. A figura 4 mostra as trocas de informação feita pelo sistema.

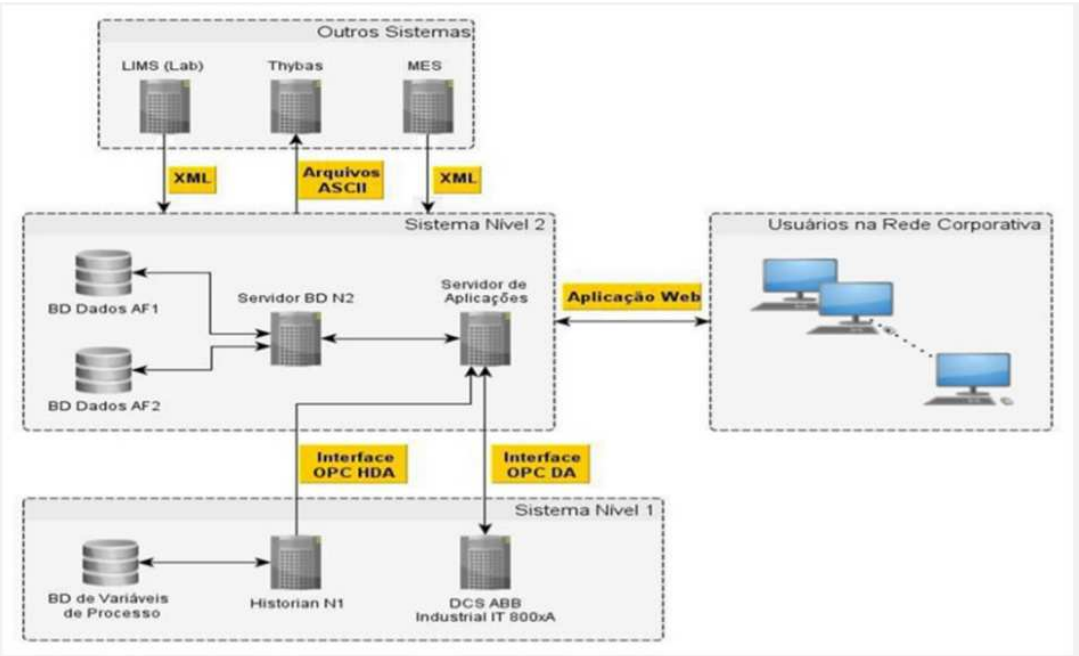

Figura 4: Topologia do Sistema Altos Fornos 


\subsubsection{Arquitetura do sistema}

O Sistema possui uma arquitetura distribuída, idealizada pela IHM Engenharia, dividido em oito processos que se comunicam através do protocolo TCP/IP, permitindo, assim a execução em uma mesma máquina ou em várias máquinas da rede. De fato, como mostra a figura 5 , os processos de comunicação com Nível 1 estão sendo executados no servidor local, enquanto que os demais, estão no servidor virtual de responsabilidade da equipe de TI da Companhia.

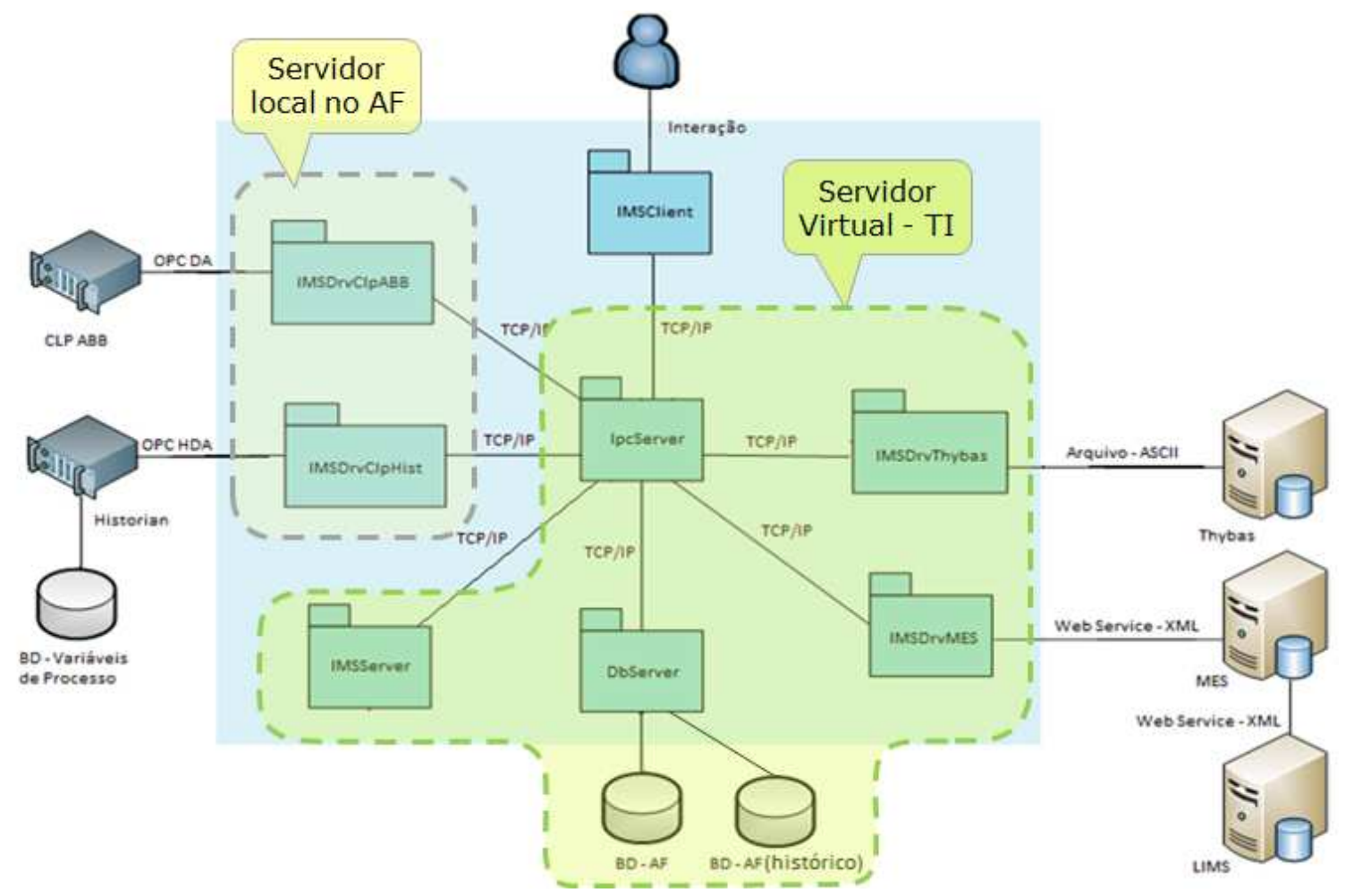

Figura 5: Arquitetura do sistema com virtualização de servidor

\section{RESULTADOS E DISCUSSÃO}

As funções do Nível 2 dos Altos Fornos estão divididas em seis grupos, de acordo com as subáreas da planta:

\subsection{Carregamento}

Conjunto de funcionalidades relativas a pesagem dos materiais e forma de distribuição durante o carregamento de material no topo do forno.

\subsubsection{Leito de fusão}

O cálculo de leito de fusão é efetuado a partir de percentual de matérias-primas na carga, análise química das mesmas e qualidade visada de gusa e escória. Como resultado tem-se qualidade da mistura que compõe a carga, qualidade do gusa e da escória, além de permitir distribuição dos materiais por silos de extração. A figura 6 mostra a tela de interface com o usuário. 


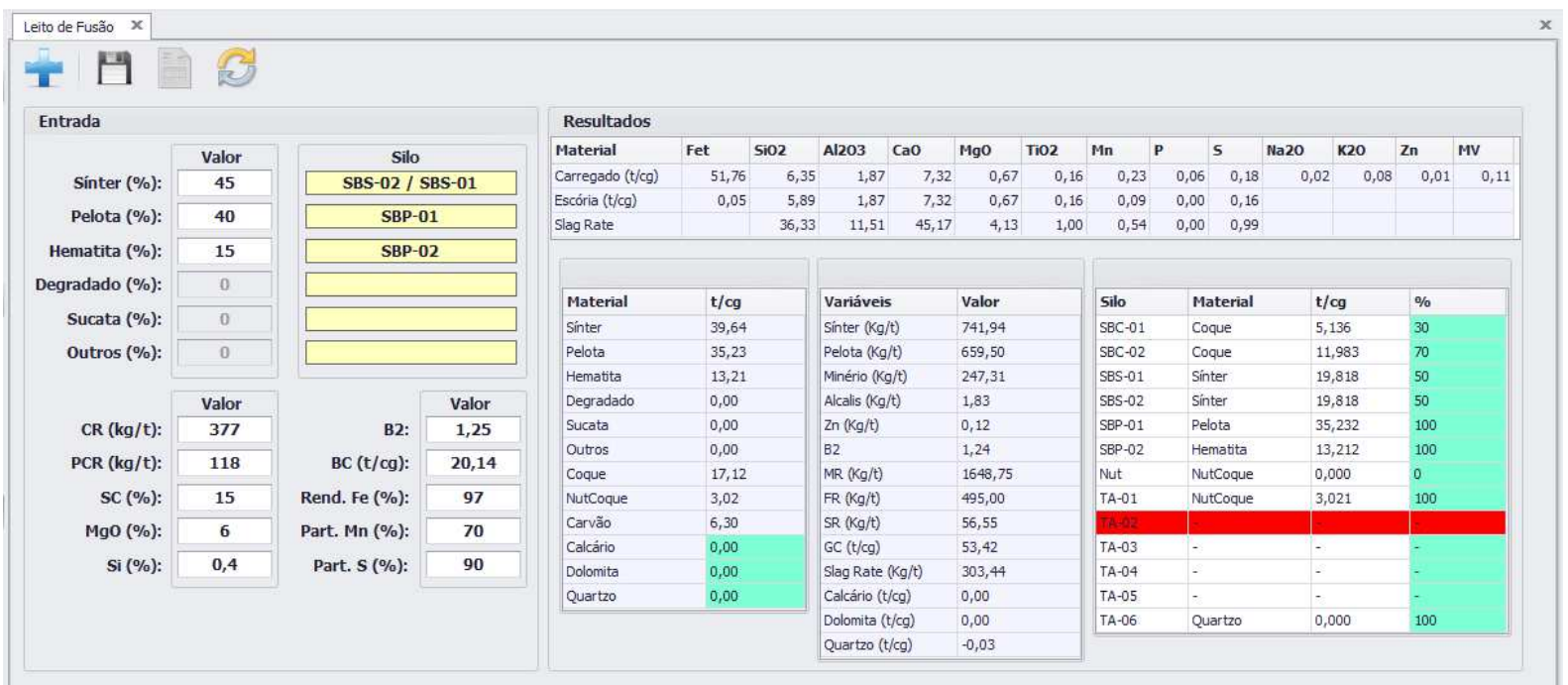

Figura 6: Cálculo de Leito de Fusão

Caso atenda a necessidade operacional, o usuário passa a editar matriz de distribuição no topo usando a tela da figura 7.

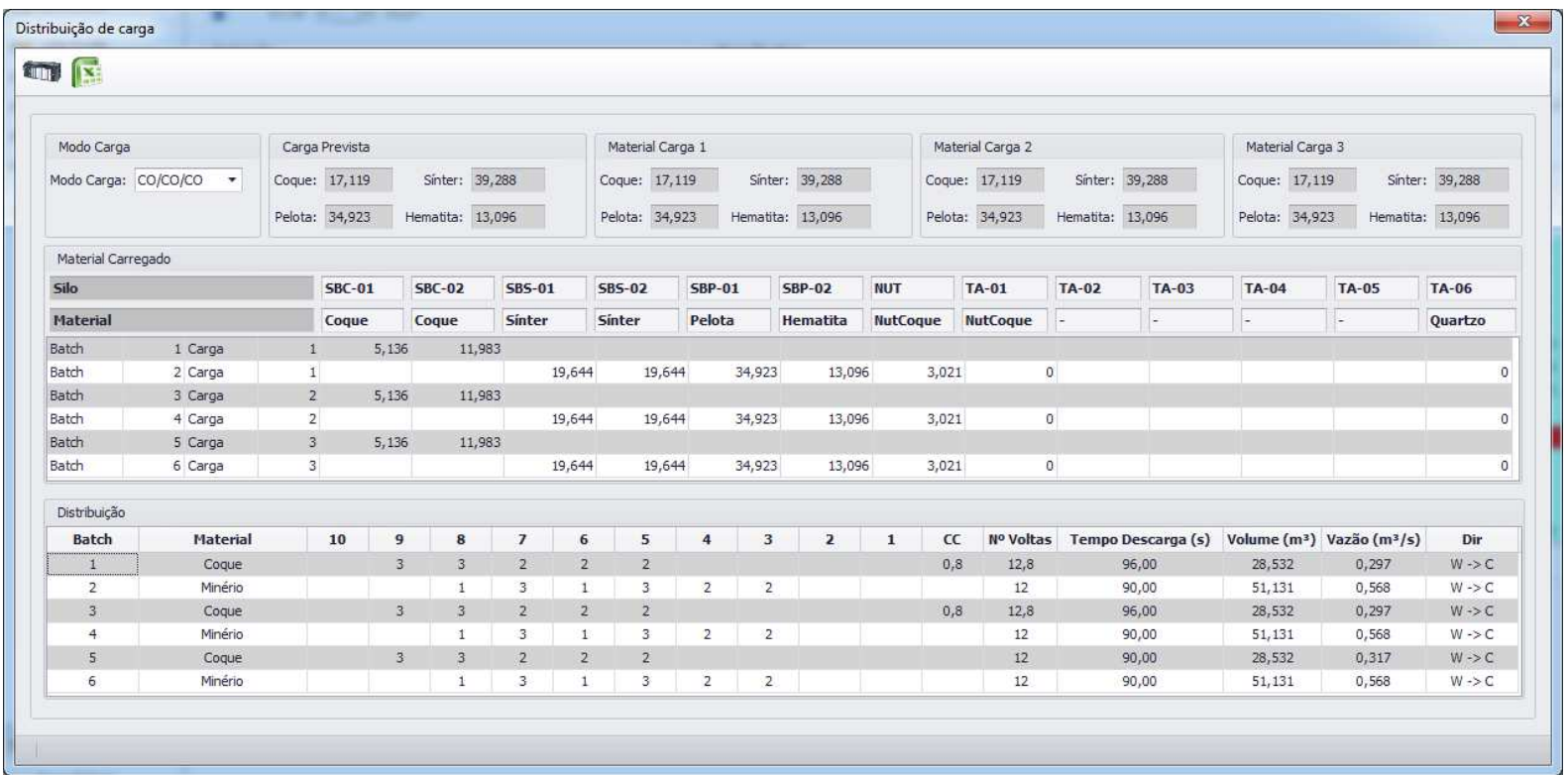

Figura 7: Edição de matriz de distribuição no topo

As matrizes de pesagem e de distribuição de descarga no topo são enviadas ao sistema de controle com o acionamento do botão correspondente da tela.

Esta tela, ainda permite a exportação de matrizes para arquivo Excel no formato originalmente usado pera Operação.

\subsubsection{Receitas}

A tela da figura 8 registra o histórico de receitas de pesagem com data de criação, autor e principais resultados do leito de fusão. Permite resgatar a receita do histórico exportando dados para a tela de cálculo de leito de fusão da figura 6 . 


\begin{tabular}{|c|c|c|c|c|c|c|c|c|c|c|c|c|c|c|c|c|c|c|c|c|c|}
\hline \multicolumn{22}{|c|}{ eceitas de Carregamentos } \\
\hline \multicolumn{22}{|l|}{18.} \\
\hline \multicolumn{22}{|c|}{ 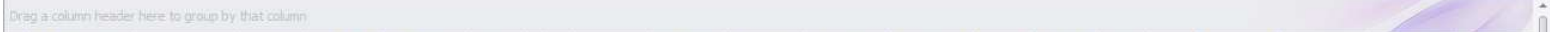 } \\
\hline Dth. Criação & Responsável & $\%$ Sinter & $\%$ Pelota & $\%$ Hematita & \% D.... & - & .. c & Cascalho... & Cakcário... & Dolomita. & $\ldots \mathrm{CR}(\mathrm{Kg} / \mathrm{t})$ & $\operatorname{PCR}(\mathrm{Kg} / \mathrm{t})$ & t) $\% 5 c$ & $\% \mathrm{MgO}$ & $\% 5 i$ & B2 & $B C(t / c g)$ & $\%$ Rend. Fe & $\%$ Part. Mn & $\%$ Part 5 & \\
\hline - 03/03/2015 13:55 & 10285099 & 45 & 40 & 15 & & 0 & & 0 & & a & 0 $\quad 377$ & & 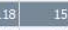 & 15 & \begin{tabular}{l|l|l|}
6 & 0,4 \\
\end{tabular} & 1,25 & 20,14 & 97 & 70 & 0. 90 & \\
\hline $03 / 03 / 201511: 48$ & 10285099 & 45 & 40 & 15 & 0 & 0 & 0 & 0 & & 0 & 377 & & 118 & 15 & 0,4 & 1,25 & 20,14 & 97 & 70 & 90 & \\
\hline 03/03/2015 09:58 & 10285099 & 45 & 40 & 15 & 0 & 0 & 0 & 0 & & 0 & 380 & & 115 & 15 & 0,4 & 1,25 & 20,14 & 97 & 70 & 90 & \\
\hline 03/03/2015 04:37 & 10286818 & 45 & 40 & 15 & 0 & 0 & 0 & 0 & & 0 & 380 & & 115 & 15 & 0,4 & 1,25 & 20,14 & 97 & 70 & 90 & 0 \\
\hline 02/03/2015 23:28 & 10286818 & 45 & 40 & 15 & 0 & 0 & 0 & 0 & & 0 & 380 & & 115 & 15 & 0,4 & 1,25 & 20,14 & 97 & 70 & 90 & 0 \\
\hline $02 / 03 / 201521: 25$ & 10286818 & 45 & 40 & 15 & 0 & 0 & 0 & 0 & 0 & 0 & 380 & & 115 & 15 & 0,4 & 1,25 & 20,14 & 97 & 70 & 90 & \\
\hline 02/03/2015 20:03 & 10285099 & 45 & 40 & 15 & 0 & 0 & 0 & 0 & & 0 & 380 & & 115 & 15 & 0,4 & 1,25 & 20,14 & 97 & 70 & 90 & 0 \\
\hline 02/03/2015 17:53 & 10285099 & 45 & 40 & 15 & 0 & 0 & 0 & 0 & & 0 & 380 & & 115 & 15 & 0,4 & 1,25 & 20,14 & 97 & 70 & 90 & 0 \\
\hline 02/03/2015 10:39 & 10285099 & 45 & 40 & 15 & 0 & 0 & 0 & 0,16 & 0 & 0 & 380 & & 115 & 15 & 0,4 & 1,25 & 20,14 & 97 & 70 & 90 & \\
\hline 02/03/2015 10:24 & 10285099 & 45 & 40 & 15 & 0 & 0 & 0 & 0,16 & & 0 & 380 & & 115 & 15 & 0,4 & 1,25 & 20,14 & 97 & 70 & 90 & \\
\hline 02/03/2015 02:25 & 10285122 & 45 & 40 & 15 & 0 & 0 & 0 & 0 & & 0 & 380 & & 115 & 15 & 0,4 & 1,25 & 20,14 & 97 & 70 & 90 & \\
\hline 01/03/2015 21:39 & 10285122 & 45 & 40 & 15 & 0 & 0 & 0 & 0 & & 0 & 380 & & 115 & 15 & 0,4 & 1,25 & 20,14 & 97 & 70 & 90 & \\
\hline 01/03/2015 20:55 & 10286818 & 45 & 40 & 15 & 0 & 0 & 0 & 0 & & 0 & 380 & & 115 & 15 & 0,4 & 1,25 & 20,14 & 97 & 70 & 90 & \\
\hline $01 / 03 / 201520: 46$ & 10286818 & 60 & 0 & 40 & 0 & 0 & 0 & 0 & & 0 & 380 & & 115 & 15 & 0,4 & 1,25 & 20,14 & 97 & 70 & 90 & 0 \\
\hline 01/03/2015 16:08 & 10286818 & 45 & 40 & 15 & 0 & 0 & 0 & 0 & & 0 & 380 & & 115 & 15 & 0,4 & 1,25 & 20,14 & 97 & 70 & 90 & 30 \\
\hline 01/03/2015 09:46 & 10286818 & 45 & 40 & 15 & 0 & 0 & 0 & 0 & 0 & 0 & 380 & & 115 & 15 & 0,4 & 1,25 & 20,14 & 97 & 70 & 90 & 0 \\
\hline $01 / 03 / 201501: 13$ & 10285122 & 45 & 40 & 15 & 0 & 0 & 0 & 0 & 0 & 0 & 380 & & 115 & 15 & 0,4 & 1,25 & 20,14 & 97 & 70 & & ${ }_{00}$ \\
\hline $28 / 02 / 2015$ 17:06 & 10286818 & 45 & 40 & 15 & 0 & 0 & 0 & 0 & 0 & 0 & 380 & & 115 & 15 & 0,4 & 1,25 & 20,14 & 97 & 70 & & 90 \\
\hline 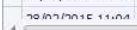 & Annocoro & $\Delta=$ & n & te & n & . & $n$ & . & . & n & son & & tie & is & A & $+n$ & $n+1$ & $n \rightarrow$ & $\mathrm{m}$ & & $\mathrm{m}^{*}$ \\
\hline
\end{tabular}

Figura 8: Registro histórico de receitas

\subsubsection{Estoque nos silos}

A análise dos materiais nos silos é obtida no sistema LIMS por meio de MES. Estes dados são disponibilizados na tela "Estoque dos Silos" mostrada na figura 9.

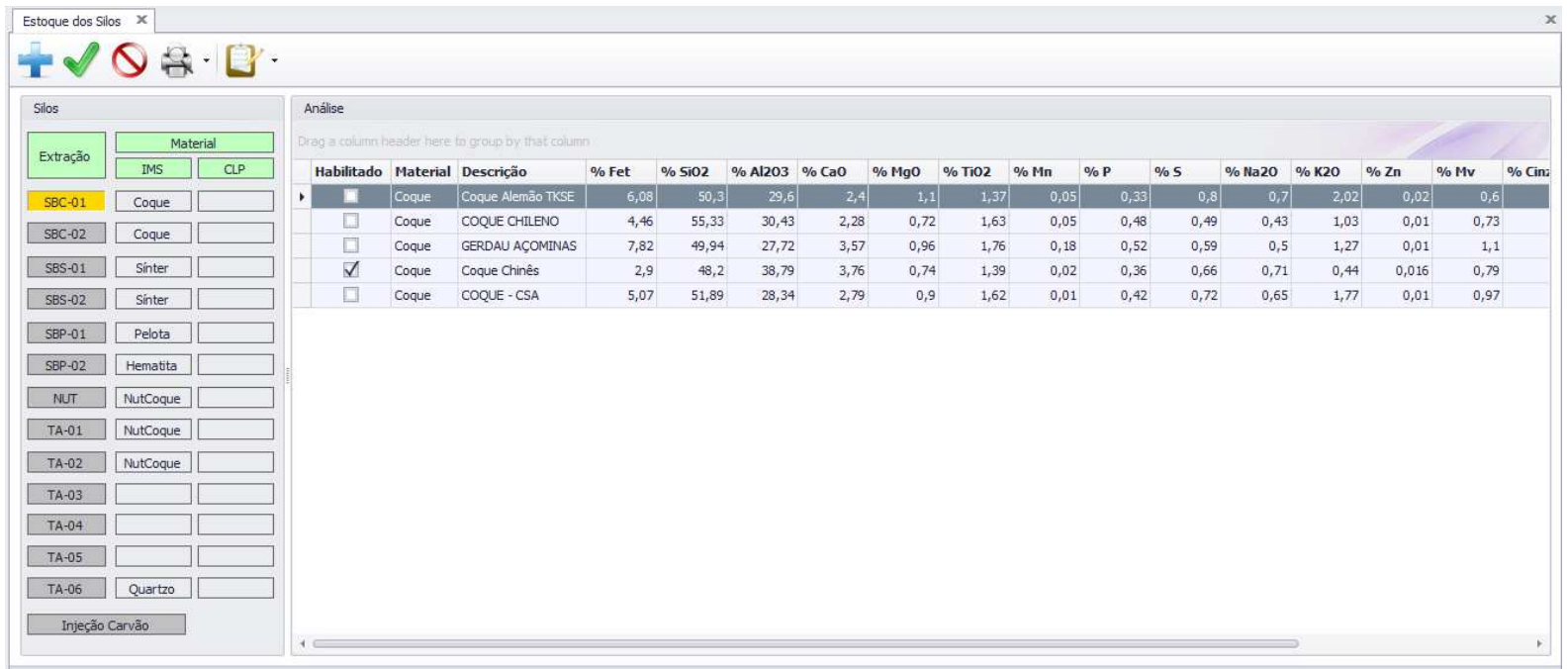

Figura 9: Análise do material nos silos

Ao habilitar uma das análises, esta será usada no cálculo de leito de fusão.

\subsubsection{Acompanhamento de descida da carga}

O resultado da alteração na carga aparece quando a mesma atinge o nível da região de cadinho. O acompanhamento de descida de cada carga ao longo do corpo forno permite visualizar o instante da manifestação no forno. Na tela da figura 10, a última carga de $n^{\circ} 46$, carregada às 09:37, aparece na primeira linha, enquanto que a carga №11, carregada às 02:20, é mostrada na última linha representando a região de cadinho. 


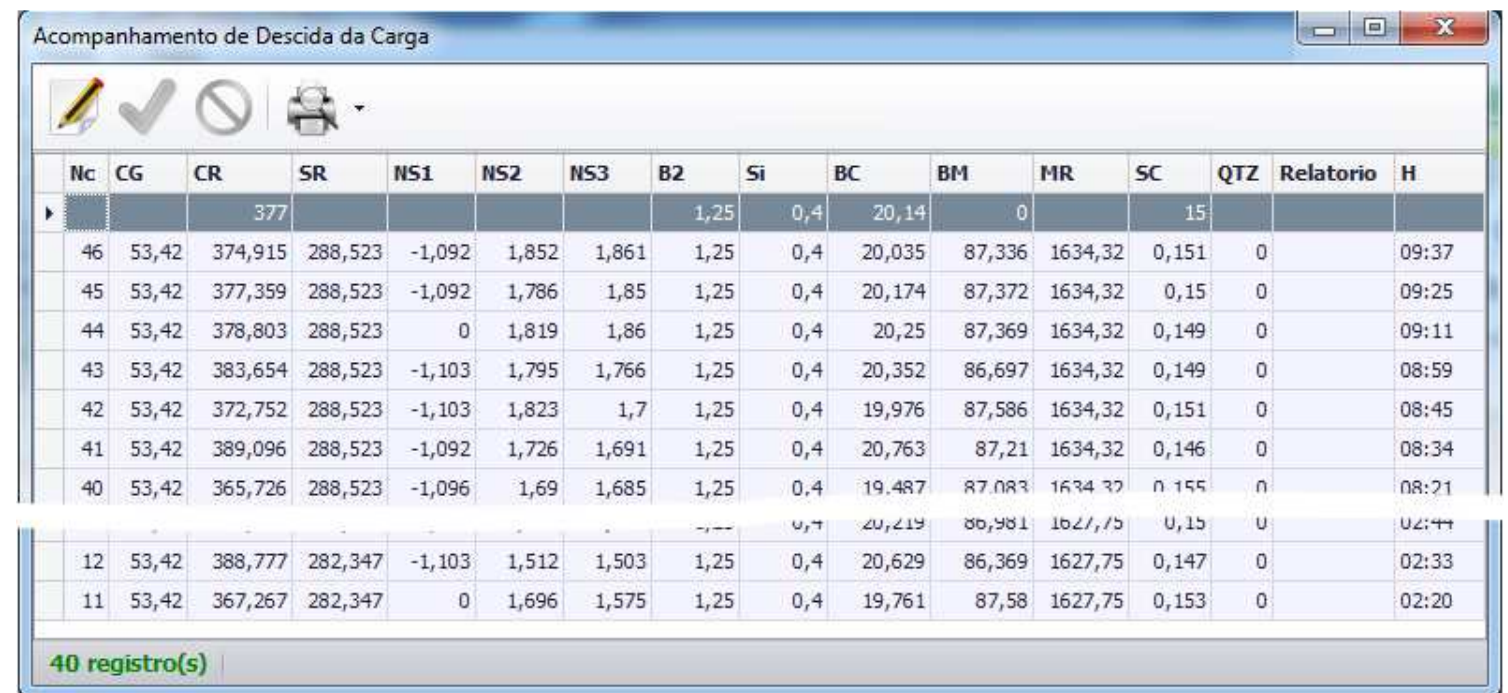

Figura 10: Acompanhamento de descida da carga no interior do forno

\subsection{Forno Próprio}

As variáveis de processo são obtidas no Nível $1 \mathrm{e}$, com base nas mesmas, os índices que representam a situação operacional são calculados. Neste grupo estão as funcionalidades do forno próprio.

\subsubsection{Dados operacionais}

As principais variáveis e os índices são mostrados em colunas de modo que, na primeira da direita aparece a média de últimos 5 minutos; na segunda, a média de últimos 30 minutos; e nas demais, médias de penúltimos e antepenúltimos 30 minutos, sucessivamente. A figura 11 mostra a disposição da tela.

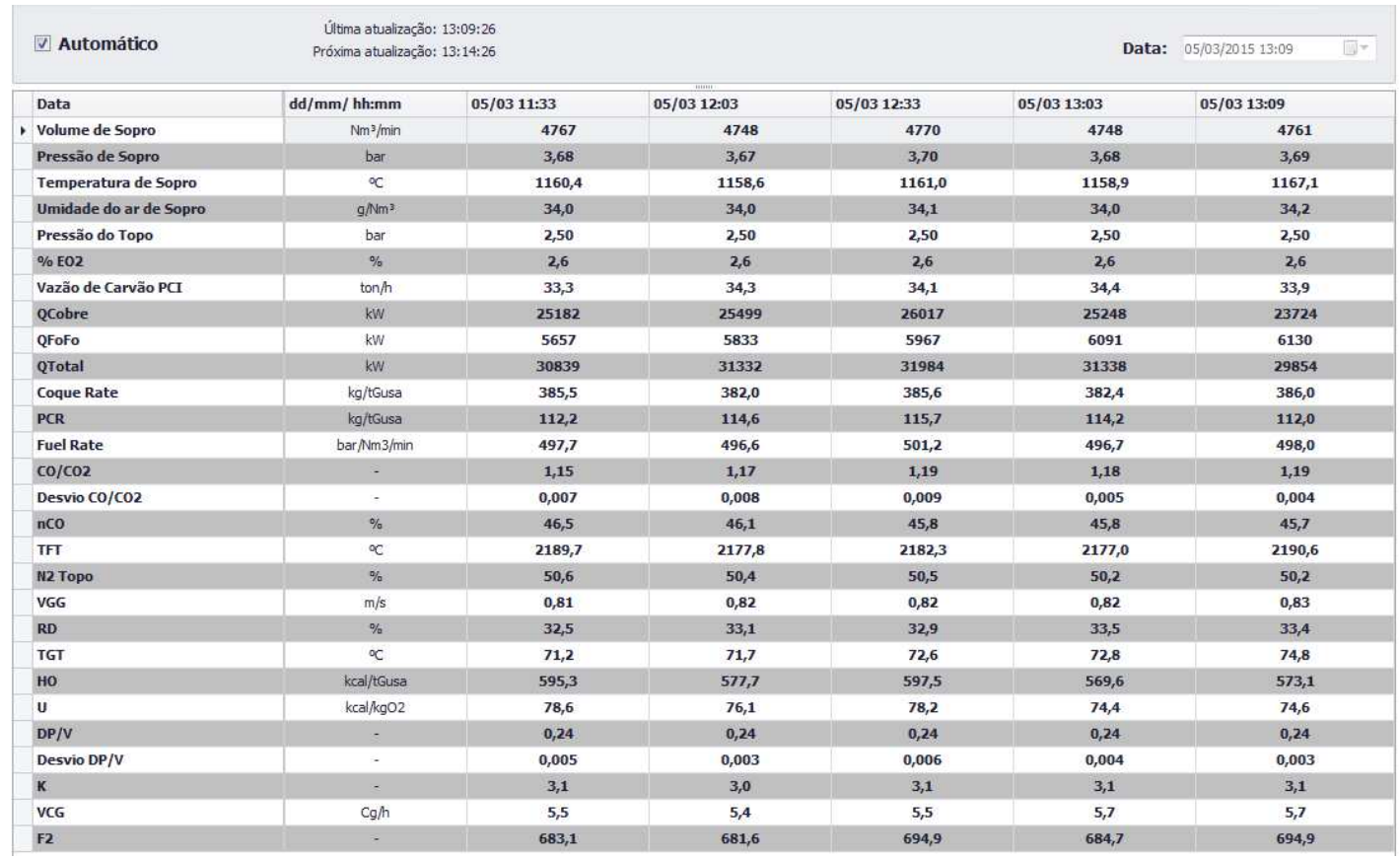

Figura 11: Dados Operacionais do Alto Forno

Estas variáveis também são disponibilizadas de forma de gráfico de tendências. 


\subsection{Corrida}

Efetua gerenciamento de corridas desde sua identificação através de atribuição de número, o início e o término de vazamentos de gusa e escória, associação de temperatura e análises recebidas do laboratório.

\subsubsection{Controle de corridas}

A tela da figura 12 mostra o resumo de cada corrida e, através desta é acessada as demais telas de manuseio de dados de panelas, temperaturas e análise de gusa/escória recebidas.

\begin{tabular}{|c|c|c|c|c|c|c|c|c|c|c|c|c|}
\hline \multicolumn{13}{|c|}{ Controle de Corridas $x$} \\
\hline, तो & I. & Es & 01 & 8 & & & & & & & & \\
\hline \multicolumn{3}{|r|}{ Núm. Corrida: } & & & 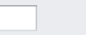 & Furo Gusa: & \multicolumn{2}{|c|}{ 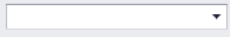 } & \multicolumn{2}{|c|}{ Equipe: } & \multicolumn{2}{|l|}{ 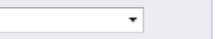 } \\
\hline & & Periodo: & 25/02/2015 00:0 & & 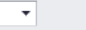 & - & 04/03/2015 & 23:59 & & & & \\
\hline Número & Furo Gusa & Hora Gusa & Hora Escória & Hora Fim & Dur. Gusa & Dur. Escória & Intervalo & Retenção Escória & Índice Escória & Equipe Vaz. & Máx. Temperatura $\left({ }^{\circ} \mathrm{C}\right)$ & $\hat{0}$ \\
\hline 15038 & 1 & 04/03 09:20 & $\quad 09: 25$ & - & - & - & 14 & 19 & - & VERDE & 1525 & \\
\hline 15037 & 2 & $04 / 0307: 38$ & $07: 50$ & 09:06 & 88 & 76 & 6 & 18 & 0,86 & AMARELA & 1524 & \\
\hline 15036 & 1 & 04/03 06:22 & $06: 31$ & $07: 32$ & 70 & 61 & 7 & 16 & 0,87 & AMARELA & 1500 & \\
\hline 15035 & 2 & 04/03 04:28 & $04: 39$ & $06: 15$ & 107 & 96 & 2 & 13 & 0,9 & AMARELA & 1497 & \\
\hline 15034 & 1 & 04/03 02:34 & $02: 55$ & $04: 26$ & 112 & 91 & 13 & 34 & 0,81 & AMARELA & 1466 & \\
\hline 15033 & 2 & 04/03 00: 18 & 00:50 & $02: 21$ & 123 & 91 & 6 & 38 & 0,74 & AMARELA & 1468 & \\
\hline 15032 & 1 & 03/03 22:17 & $22: 21$ & $00: 12$ & 115 & 111 & 9 & 13 & 0,97 & AMARELA & 1458 & \\
\hline 15031 & 2 & 03/03 20:41 & $20: 45$ & $22: 08$ & 87 & 83 & 5 & 9 & 0,95 & AMARELA & 1476 & \\
\hline 15030 & 2 & 03/03 18:51 & 19:14 & $20: 36$ & 105 & 82 & 11 & 34 & 0,78 & AZUL & 1477 & \\
\hline 15029 & 2 & $03 / 0316: 58$ & $17: 25$ & $18: 40$ & 102 & 75 & 18 & 45 & 0,74 & AZULL & 1508 & \\
\hline 15028 & 1 & $03 / 0315: 20$ & $15: 36$ & $16: 40$ & 80 & 64 & 10 & 26 & 0,8 & AZUL & 1499 & \\
\hline 15027 & 2 & 03/03 13:51 & 14:00 & $15: 10$ & 79 & 70 & 11 & 20 & 0,89 & AZUL & 1504 & \\
\hline 15026 & 1 & 03/03 12:30 & $12: 38$ & $13: 40$ & 70 & 62 & 4 & 12 & 0,89 & AZULL & 1474 & \\
\hline 15025 & 2 & 03/03 10:35 & $10: 55$ & 12:26 & 111 & 91 & 9 & 29 & 0,82 & AZUL & 1504 & \\
\hline 15024 & 1 & 03/03 07:55 & $08: 26$ & 10:26 & 151 & 120 & 14 & 45 & 0,79 & AZUL & 1493 & \\
\hline 15023 & 2 & 03/03 06:45 & 07:05 & $07: 41$ & 56 & 36 & 10 & 30 & 0,64 & AMARELA & 1526 & \\
\hline
\end{tabular}

Figura 12: Controle de Corridas

\subsubsection{Gráfico de corridas}

A tela "Relatório de Corridas" da figura 13 mostra o gráfico de vazão de escória no granulador que, em combinação com o gráfico de barras de início e termino de vazamentos, evidencia a veracidade dos dados.

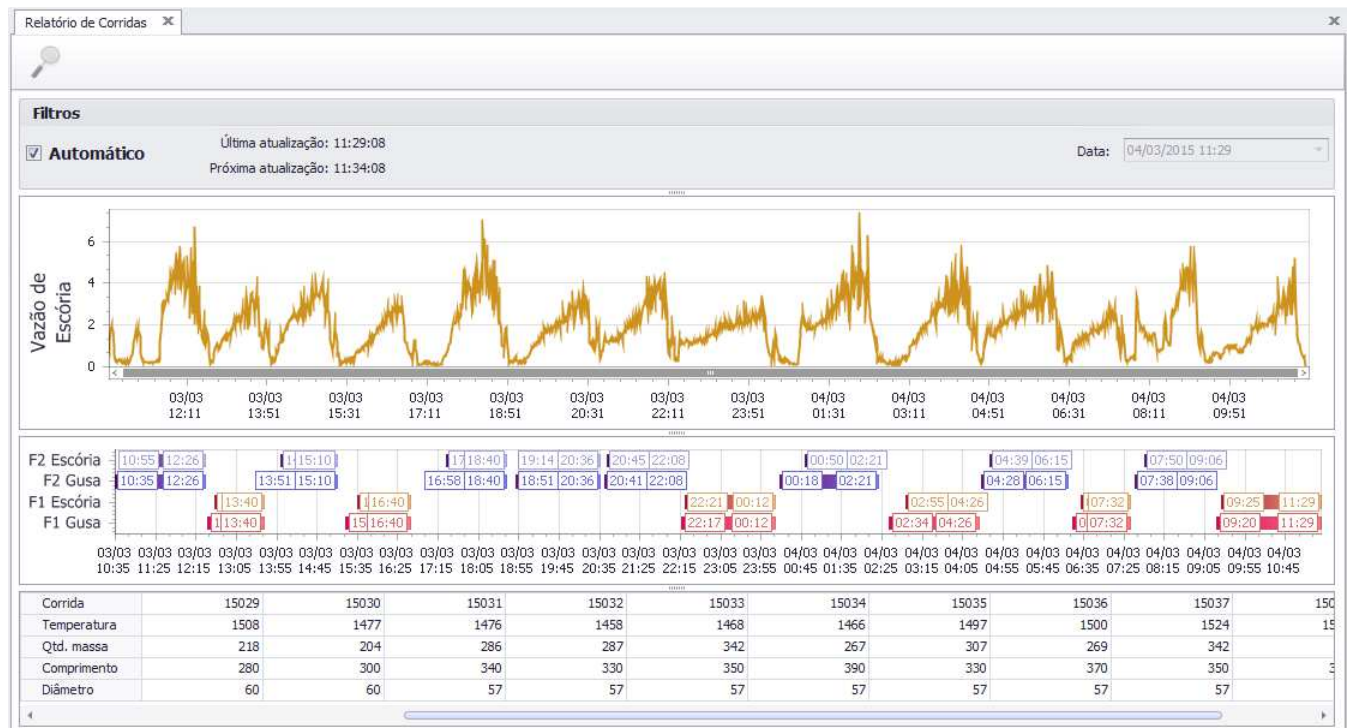

Figura 13: Relatório de Corridas 


\subsection{Regeneradores}

As informações de início e término das fases de combustão e sopro, que compõe um ciclo, são registradas juntamente com volumes de combustíveis e de ar soprado, pressões e temperaturas obtidas no processo.

\subsection{Monitoração Térmica}

A supervisão térmica do corpo do forno é um item muito importante na vida útil do forno. Com esta finalidade o forno possui próximo de 500 termopares. Estes dados são disponibilizados na forma de mapa térmico (figura 14), distribuição térmica seccional e gráfico de tendência.

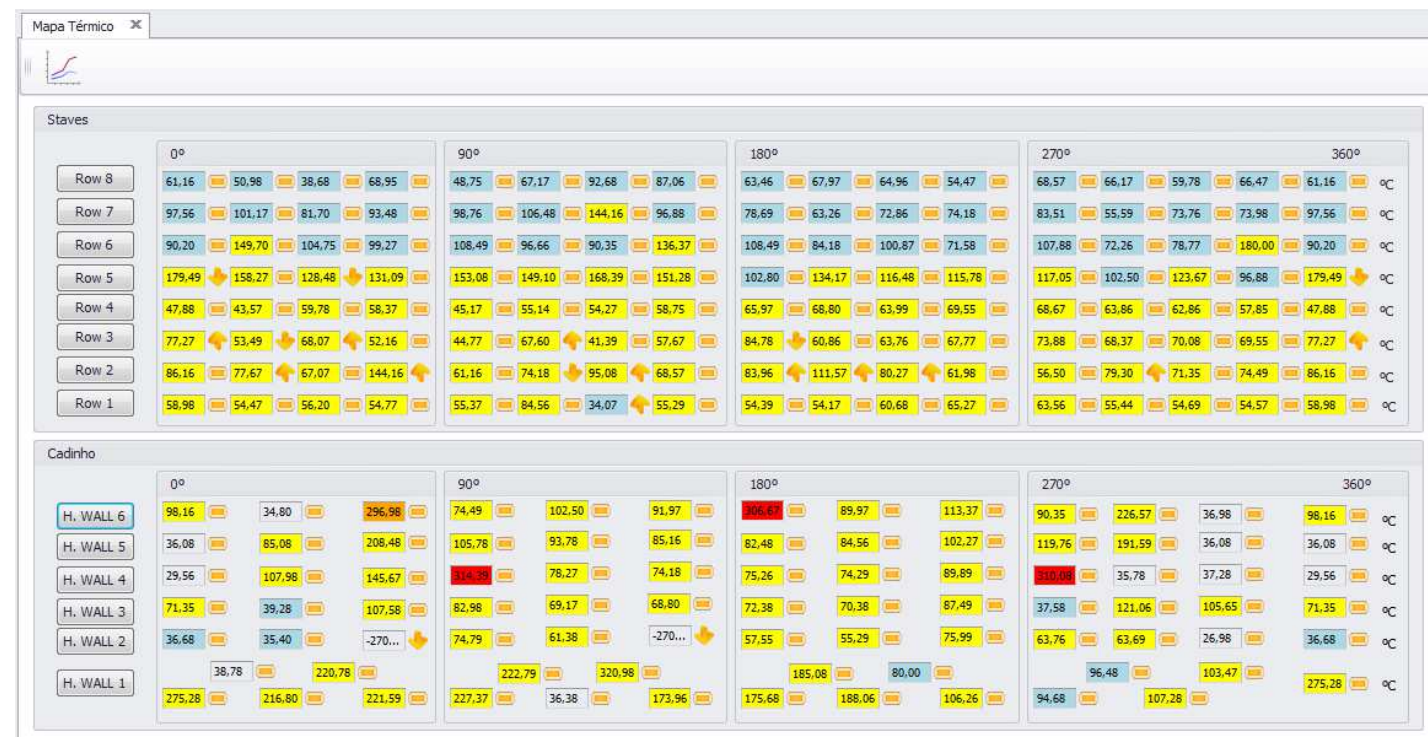

Figura 14: Mapa térmico do forno

\section{CONCLUSÃO}

A primeira fase do sistema que contemplava gerenciamento de corridas entrou em operação em maio de 2013 e as demais, em dezembro do mesmo ano. Desde então tem apresentado desempenho bastante satisfatório, atendendo as expectativas da implementação, a ponto de motivar a introdução de Nível 2 nas demais áreas da Redução (planta de coqueria, pátio de matérias-primas e sinterização).

\section{REFERÊNCIAS}

1 GREERDES M, TOXOPEUS H, VLIET CV. Modern Blast Furnace Ironmaking - An Introduction. $2^{\mathrm{a}} \mathrm{Ed}$. 2009. Cap. 1.

2 Lean Validation, How to use ISA-95 [página da internet]. [Acesso em 05/03/2015].

Disponível em http://www.leanvalidation.eu/index.php/isa-standards/isa-95 